\title{
KAJIAN BENTUK DAN SIMBOL KUJANG SUNDA
}

\section{Hendri Saifulhayat}

\author{
Fakultas Pascasarjana Program Studi Magister Desain \\ Universitas Komputer Indonesia \\ Jl. Dago (Ir. H. Djuanda) 160-162, Bandung, 40132 \\ e-mail: hendrisherres@gmail.com
}

$\begin{array}{llll}\text { Received: } \mathrm{n} / \mathrm{a} & \text { Revised: } \mathrm{n} / \mathrm{a} & \text { Accepted: } \mathrm{n} / \mathrm{a} & \text { Published: 2018-09-14 } \\ \text { Editor: Abay D Subarna } & \text { Reviewer: n/a } & & \end{array}$

\begin{abstract}
Kujang is known and considered as a weapon tradition that represents Sundanese society culture. Looking back, that a knife is the development of a sharp-sided discovery made up of rocky chunks of kalcedon that make humans rank first in the food chain on the face of the earth. The knife transforms into a long sword, thrown into a spear, jagged into a saw, squeezed with axis into scissors and many other more specific functions into a variety of tools because of the growing demands of life needs. Kujang comes from Kudi Hyang. Kudi is functionally a farming tool that is prepared to honor and worship Hyang, the supreme ruler of the universe. The concept of Kujang is far from the utility function of a tool or a weapon. Kujang is a symbolic artifact that functions intrinsically, and not a weapon, because planning from the beginning can be distinguished by making weapons. Then Kujang in form follows function proven not to fulfill utility requirement. Kujang which is identified with the term "nyumput buni dinu caang" or hidden in a visible / bright place, can be fully revealed through a scalpel of Sundanese cultural teaching that is Panca Niti or five stages of understanding. This teaches us to understand something more deeply, from the meaning, meaning, nature, divinity and understanding in a comprehensive way. Kujang is loaded with full of spectacle, guidance, teaching or education to the state, and the potential will be revealed more positive things behind its appearance.
\end{abstract}

Keywords: Design; Fine Art; Sundanese; Ritual Weapons; Tosan Aji..

\begin{abstract}
Abstrak. Kujang dikenal dan dianggap sebagai senjata tradisi yang merepresentasikan budaya masyarakat Sunda. Melihat ke belakang, bahwa sebilah pisau merupakan pengembangan dari temuan sisi tajam yang terbentuk atas serpihan batu sejenis kalsedon yang menjadikan manusia menduduki peringkat utama dalam mata rantai makanan di atas muka bumi. Pisau bertransformasi memanjang menjadi pedang, dilontarkan menjadi tombak, bergerigi menjadi gergaji, dihimpitkan dengan sumbu menjadi gunting dan masih banyak fungsi lain yang semakin spesifik menjadi berbagai alat bantu karena tuntutan kebutuhan hidup yang semakin berkembang. Kujang berasal dari kata Kudi Hyang. Kudi secara fungsi merupakan perkakas pertanian yang dipersiapkan untuk menghormati dan memuja Hyang, penguasa tertinggi alam semesta. Konsep perupaan Kujang jauh dari kebutuhan fungsi utilitas sebuah alat bantu ataupun sebilah senjata. Kujang merupakan artefak simbolis yang berfungsi intrinsik, dan bukan senjata, karena perencanaan sejak awal dapat dibedakan dengan membuat senjata. Kemudian Kujang secara bentuk mengikuti fungsi terbukti tidak memenuhi kebutuhan utilitas. Kujang yang diidentikan dengan istilah "nyumput buni dinu caang" atau tersembunyi di tempat yang terlihat / terang, dapat diungkap secara lengkap melalui pisau bedah ajaran budaya Sunda yaitu Panca Niti atau lima tahapan pemahaman. Ajaran ini memberi petunjuk untuk memahami sesuatu secara lebih mendalam, mulai dari arti, makna, alamiah, ketuhanan dan pemahaman secara menyeluruh. Kujang sarat dengan muatan tontonan,
\end{abstract}


tuntunan, ajaran atau edukasi hingga ke-tata-negaraan, dan potensial akan dapat diungkap lebih banyak lagi hal positif dibalik perupaannya.

Kata kunci: Budaya Sunda; Desain; Seni Rupa; Senjata Ritual; Tosan Aji.

\section{PENDAHULUAN}

Perubahan merupakan perjalanan mutlak bagi manusia sebagai makhluk sosial, dimana kemajuan merupakan hasil olah pemikiran individu yang dipakai pada suatu perkembangan kebudayaan manusia sejak jaman prasejarah. Manusia berada pada lingkungan geografis didalam masa tertentu. Perkembangan budaya menghasilkan kemajuan di berbagai bidang kehidupan. Berawal dari perkakas untuk kebutuhan berburu, mengolah makanan, hingga senjata untuk mengatasi ancaman binatang buas, dan musuh dari luar kelompoknya. Peralatan bantu seperti pisau pada awalnya dibuat dengan material batuan kalsedon, obsidian dan lainnya, yang dibuat dengan proses yang masih sederhana.

Ditemukannya bahan-bahan baku baru kemudian mengakibatkan perkembangan teknologi dalam menciptakan benda fungsional sejenis pisau. Pengembangan produk melahirkan penyempurnaan, ada yang tetap , berubah, baru, ditinggalkan bahkan hilang.

Pisau sebagai alat potong harus memiliki persyaratan, yaitu memiliki dua bagian terdiri dari bagian sisi tajam dan bagian lain sebagai pegangan. Pada masa awal dapat dikenali sebuah alat kerat atau potong bernama pisau yang belum memiliki bagian sebagai pegangan. Berbagai artefak diduga pisau ditemukan memiliki bentuk bulat, lonjong atau panjang dengan sisi tajam di sekelilingnya. Sejak jaman prasejarah kebutuhan peralatan dibuat menggunakan bahan baku yang berada di wilayah sekitarnya, seperti tulang, batu, gigi binatang dan kayu. Salah satu yang menarik adalah alat potong, kerat atau sayat bernama pisau yang mengalami beberapa periode perkembangan zaman.

Fungsi sebuah pisau pada Periode Palaeolithikum, untuk memenuhi kebutuhan berburu, mengumpulkan makanan serta memasak. Pada zaman ini dikenal sebagai masa berburu dan mengumpulkan makanan, alat bantu masih sederhana memakai bahan baku batu kalsedon, kayu dan tulang termasuk gigi binatang.

Temuan pada masa ini berupa serpihan batu jenis kalsedon sepanjang $10 \mathrm{~cm}$ diduga berusia sekitar 40.000 tahun SM dan juga batuan tajam bergerigi sepanjang $20 \mathrm{~cm}$ dari sekitar $2.500-$ 10.000 tahun SM. Wujud fisikalnya sangat sederhana, di mana sebuah pisau batu berbentuk hampir bulat, lonjong atau setengah lingkaran dan masih tanpa pegangan (Gambar 1). Memasuki periode Mesolithikum, kelompok kecil manusia mulai menetap di gua-gua, peralatan mengalami perkembangan karena penyesuaian kebutuhan, dari masa berburu yang nomaden kemudian mulai menetap dan bercocok tanam. Pada masa ini pembuatan peralatan seperti pisau sudah semakin halus dan mulai menerapkan prinsip fungsi. Bentuk 'form follow function' bisa dikenali pada sebilah pisau dengan material batu kalsedon dan obsidian. Sebilah pisau sudah menjadi dua bagian, yaitu sisi tajam dan pegangan.

Perkembangan kemudian berlanjut pada Periode Neolithikum, dimana sebuah pisau sudah semakin halus karena ditemukannya teknologi pemolesan. Teknologi pengecoran logam dimulai pada Zaman Perunggu sekitar 2500 tahun SM.

Pada zaman ini pisau menjadi semakin kuat, tidak serapuh bahan baku batu yang cenderung rentan saat terjatuh atau berbenturan dengan bahan lain yang lebih kuat. Teknologi logam berkembang melahirkan beragam produk seperti pisau, kapak, pedang, tombak dan lainnya, yang berfungsi sebagai senjata tajam dan perkakas.

Berdasarkan hasil observasi, kajian pustaka dan wawancara ada pula karya logam yang memiliki fungsi simbolis dan filosofis. Fenomena tersebut dapat dikenali dari struktur bilahnya secara detil, ada kecurigaan bahwa karya logam tersebut tidak difungsikan sebagai alat bantu (utilitas), kemungkinan berfungsi sakral atau simbolis. 


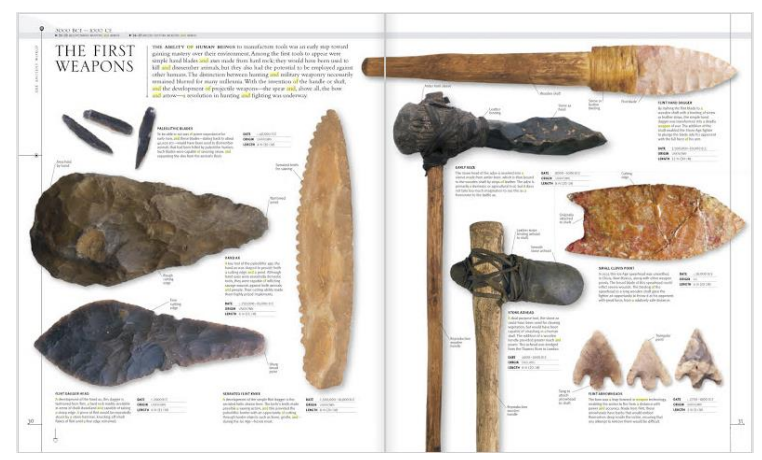

Gambar 1 Temuan bilah tajam yang menjadi cikal bakal sebilah pisau.

\section{METODE}

Penelitian ini menggunakan metoda kualitatif yang berdasar pada analisa data. Sasaran atau obyek penelitian kujang dibatasi jenisnya atas beberapa sampel fisik agar data yang diambil dapat digali sebanyak mungkin, serta agar penelitian ini tidak dimungkinkan adanya pelebaran obyek penelitian. Dalam kajian ini dipergunakan metode deskripsi analisa mengenai berbagai gejala perupaan yang terdapat pada bilah kujang secara morfologi, meliputi dimensi atau ukuran panjang dan lebar, karakter logam, disiplin bentuk perupaan atau dapuran, kualitas logam, kualitas teknis pengolahan atau garap, pamor atau guratan pada bilah, estimasi periode penciptaan, dan jumlah lubang yang terdapat pada bilahnya. Penelitian ini diperkaya dengan beberapa disiplin ilmu yang mendukung, dimana berbagai data dikumpulkan dan komparasikan sehingga mengerucut pada objek penelitian.

\section{HASIL DAN PEMBAHASAN}

Budaya merupakan hasil totalitas dari rasa, karsa, cipta dan karya manusia dalam peradaban yang melahirkan teknologi salah satunya berupa peralatan spesifik yang dapat menjadi tolak ukur kemajuan atau kualitas tertentu. Peradaban membentuk adat yang menjadi nilai kebiasaan yang diwariskan secara turun temurun menjadi tradisi, lalu kemudian tradisi akan menjadi nilai berupa edukasi.

Tosan Aji atau Wesi Aji adalah merupakan karya seni tempa logam dalam bentuk bahasa rupa simbolis yang merupakan representasi dari peradaban Nusantara di masa lalu. Setiap bilah Tosan Aji merupakan rangkaian sistem yang berhubungan, kaitan tersebut menerangkan dimensi waktu seperti periode penciptaan/ penangguhan, dimensi ruang seperti wilayah sebaran, teknologi khususnya logam, kemudian nilai-nilai filosofis dan simbolis. Masing-masing jenis Tosan Aji memiliki latar belakang pencipta seperti Mpu, Guru Teupa, atau Panday yang merekam riwayat hidup para pemegang/ pemesannya.

Kujang merupakan karya nyata peradaban Nusantara yang berkembang diantara banyak pusaka Nusantara lainnya. Melalui proses yang panjang hingga melahirkan transformasi bentuk yang berkembang jauh dari bentuk awalnya yaitu Kudi, yang merupakan benda fungsional pada awalnya dipakai sebagai perkakas pertanian. Kelahiran Kujang adalah sebagai tujuan penciptaan Kudi Hyang dimana artinya mendekati sebagai perkakas yang ditujukan dalam area penghormatan atau kepercayaan kepada Yang Maha Kuasa. Hal ini dapat dimengerti karena masyarakat budaya Sunda merupakan bangsa agraris yang mengerti siklus yang terjadi dengan pola yang tetap. Langit memberikan kehidupan dengan air hujannya yang turun membasahi bumi sehingga harmoni tersebut membuahkan hasil berupa panen dalam relitasnya. Perkawinan dunia atas dan dunia bawah yang berbeda dihubungkan dunia tengah yang menjadikannya harmoni dalam kehidupan.

Proses penciptaan kujang dilatarbelakangi sejarah yang sangat panjang, dan berdasarkan bukti hasil temuan, banyak diantara kujang yang diperkirakan dibuat sebelum zaman Pajajaran. Bahkan ada peneliti kujang yang menyatakan bahwa kujang telah ada sejak zaman Taruma Nagara. Meski 
kujang tidak pernah ditulis dalam prasasti, banyak bukti yang memperkuat keberadaanya, seperti; situs megalithik Batu Kujang di daerah Sukabumi, temuan perkakas kudi di kompleks candi Batujaya Karawang, relief candi Sukuh di Surakarta, catatan Sir Stamford Raffles dalam buku "the History of Java" dan sebagainya (Gambar 2).

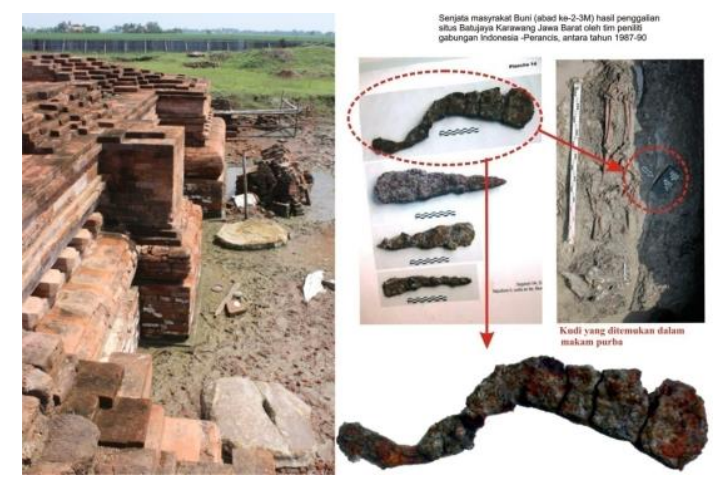

Gambar 2. Bukti Keberadaan Kujang Purba di Kompleks Candi Batujaya Kab. Karawang

Semua penamaan bentuk perupaan kujang, memiliki kecenderungan mendekati gejala Mimesis atau karya seni merupakan hasil tiruan bentuk. Dengan kata lain kujang merepresentasikan bentuk tertentu yang memiliki kesamaan atau kemiripan dengan bentuk yang diambil dari alam. Penegasan lain perupaan struktur bentuk pusaka, apabila kita melihat perspektif sejarah kenegaraan, sesungguhnya kujang sebagai simbolisasi atau lambang dari ajaran negara.

Penciptaan kujang atau Kudi Hyang merupakan pengembangan dari Kudi yaitu perkakas pertanian yang kemudian bertransformasi hingga banyak varian bentuk perupaan, karena berada dan berkembang di bawah otoritas kerajaan.

Varian bentuk perupaan kujang mengambil esensi bentuk burung; kujang ciung atau bahasa rupa yang menunjuk kepada esensi ajaran budaya Sunda. Kata Ciung, dalam nama dapuran kujang merupakan sebuah siloka atau personifikasi. Ciung menerangkan makna $\mathrm{Ca}$ 'ang yang berarti sebuah pencerahan dalam konteks spiritual (Gambar 3). Perupaan kujang selain peminjaman bentuk burung adapula bentuk unggas lain seperti bangau; kujang bango, ayam; kujang jago, garuda; kujang galudra. Peminjaman bentuk binatang berkaki empat seperti badak; kujang badak, gajah; kujang liman, kuda; kujang turangga, kerbau; kujang andini, kijang; kujang kidang, macan; kujang martasinga. Kujang lain dari peminjaman bentuk katak; kujang bangkong, bentuk figuratif; kujang wayang, bentuk mitologi; kujang naga.

Suatu penelitian mendalam telah menunjukkan varian kujang dalam kelompok penamaan yang beragam merupakan peminjaman nama atas tiruan bentuk dari flora dan fauna yang berada dalam lingkungan ruang dan waktu dalam kebudayaan Sunda (Gambar 4). Melalui metoda pembacaan disiplin Panca Niti atau Lima Tahapan Ilmu yang merupakan tahapan pembacaan atas apa yang tersirat, yang tersurat hingga makna yang lebih dalam dan kemudian menjadi edukasi atau tuntunan bagi para penguasa dalam menjalankan pemerintahan.

Kujang Ciung dalam tahapan Niti Harti, Ciung bermakna Manuk. Perupaan bilahnya sebagai bentuk substansi atau esensi dari bentuk burung.

Tahapan Niti Surti, melihat Esensi makna dari Ciung adalah kata "Ca'ang", mengarahkan pada Buana Nyungcung, yang merupakan tempat yang paling tinggi kedudukannya.

Pada tahapan Niti Bakti, Asal kata "Ciung" dari Manuk yang bermakna manusia. Pemaknaan terhadap gelar manusia bersih atau yang sudah mendapatkan pencerahan makna dari kata "Ca'ang" bermakna bersih yang menunjuk pada seorang tokoh raja.

Niti Bukti merupakan tahapan lanjut Manusia yang sudah mencapai tingkat $\mathrm{Ca}$ 'ang ini memberikan contoh berupa ajaran kepada masyarakat melalui perilakunya.

Tahapan terakhir adalah Niti Sajati, ajaran tersebut menjadi keilmuan baru yang dijadikan pedoman-pedoman untuk para penguasa berikutnya. 


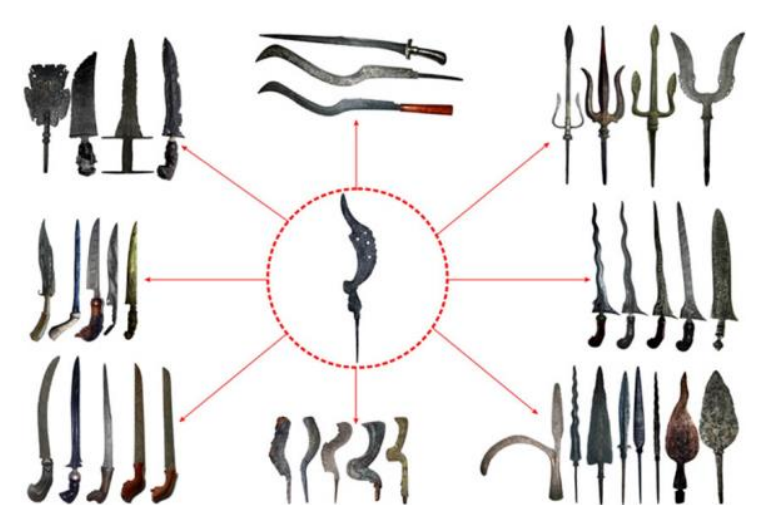

Gambar 3. Kujang Ciung representasi Masyarakat Budaya Sunda diantara Tosan Aji Nusantara.

Kujang Ciung merupakan salah satu jenis kujang yang populer dan berkembang, dianggap sebagai senjata khas Jawa Barat, sehingga kujang Ciung dapat dijadikan sebagai wujud representatif dari Kujang Sunda. Di samping itu, bentuk perupaan kujang Ciung merupakan simbol yang dapat mengungkap makna filosofis, simbolis, kosmologi Sunda.

Bentuk bilah kujang Ciung memiliki memiliki nilai estetika dengan ujung yang runcing dengan bagian sisi-sisinya yang tajam, tetapi tidak meiliki unsur efisien, efektif dan ergonomis.

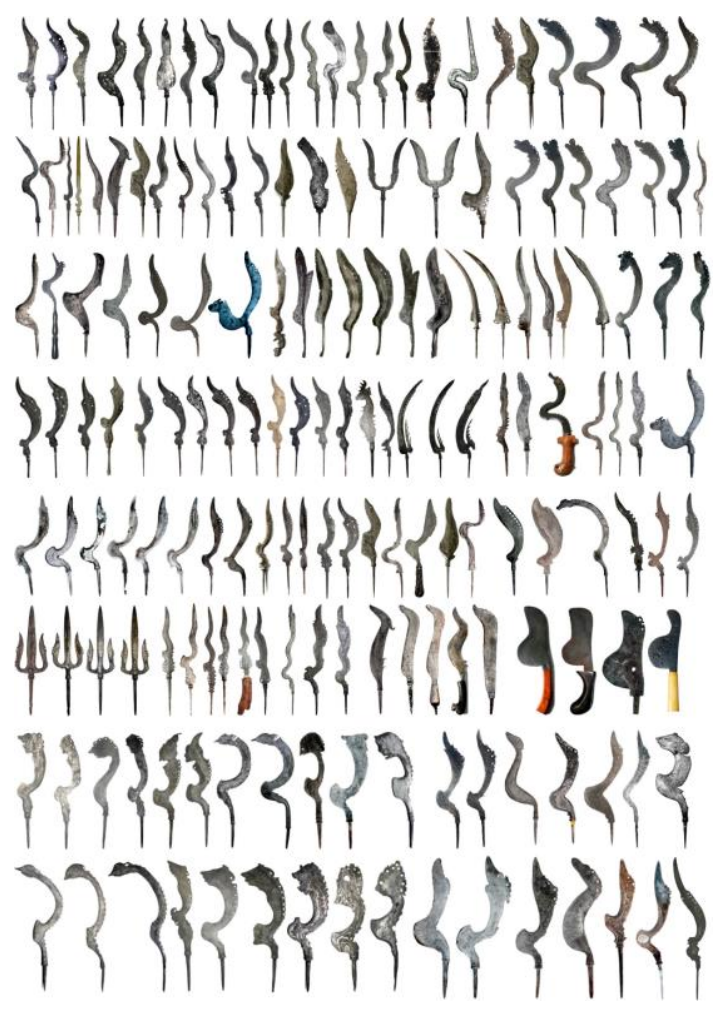

Gambar 4. Varian Perupaan Kujang Sunda

Periode penciptaan atau penangguhan kujang yang tertua dinamakan kujang Kuno, Budho atau tangguh Budho estimasi sekitar tahun 125-1125 Masehi pada era kekuasaan raja-raja Salakanagara menjelang Kerajaan Tarumanagara. Era Kuno Pertengahan atau Kuno Madya estimasi antara tahun 1126-1250 Masehi dikenal sebagai tangguh Pajajaran lalu tangguh Pertengahan yaitu estimasi antara tahun 1400-1613 Masehi sebagai tangguh Cirebonan. 
Fungsi kujang berhubungan dengan dimensi atau ukuran dari bilahnya. Fungsi Kujang tersebut diantaranya; Kujang berukuran kecil antara $10-15 \mathrm{~cm}$ biasanya termasuk katagori kujang pajimatan atau jimat. Kujang yang berukuran sedang $20-35 \mathrm{~cm}$ biasanya termasuk katagori kujang pusaka. Kujang yang berukuran besar $40-50 \mathrm{~cm}$ termasuk dalam katagori kujang pakarang yang secara fungsi menjadi bilah atau mata tumbak. Kujang yang berukuran dari $50-75 \mathrm{~cm}$ digolongkan ke dalam katagori kujang pangarak yang berfungsi sebagai simbol atau panji kebesaran negara.

\section{KESIMPULAN}

Kujang merupakan artefak simbolis dan bukan senjata, karena tidak memiliki syarat lengkap sebagai benda fungsional. Hal ini didasarkan pada bentuk perupaan bilahnya, dimensi,tidak memiliki syarat efektif, efisien dan ergonomis.

Kujang yang dikenal dengan istilah "nyumput buni dinu caang” atau tersembunyi ditempat yang terlihat, dapat diungkap secara lengkap dengan Panca Niti yang merupakan lima tahapan ajaran Budaya Sunda yang mengajarkan untuk melihat sesuatu secara lebih mendalam dari apa yang terlihat secara kasat mata. Kujang sarat dengan muatan tontonan, tuntunan, ajaran atau edukasi hingga ketatanegaraan. Sangat potensial di masa mendatang dapat diungkap sesuatu yang lebih banyak hal positif dibalik perupaannya.

\section{DAFTAR PUSTAKA}

[1] Holmes, Richard (2008) WEAPON: A Visual History of Arms and Armour.Pensylvania, DK Publishing.

[2] Jessup, Helen Ibbitson (1990) Court Arts of Indonesia.New York, Pbk

[3] Kurniawan, Aris (2011), Kajian Filosofis dan Simbolik Kujang, Tesis, Program Pascasarjana FSRD- ITB

[4] Moebirman (1978) Keris and Other Weapons of Indonesia.Jakarta, Yayasan Pelita Wisata.

[5] Peursen, Cornelis Anthonie (1976) Strategi Kebudayaan.Jakarta, Kanisius

[8] Raffles, Thomas Stamford, (2008), The History of Java, Narasi: Yogyakarta

[9] Sumardjo, J. (2004) Hermeneutika Sunda: Simbol-Simbol Babad Pakuan/Guru Gantangan, Kelir, Bandung

[10] Sumardjo, J. (2006) Estetika Paradoks. Bandung: Sunan Ambu Press.

[11] Sumardjo, J. (2003) Simbol-simbol Artefak Budaya Sunda: Tafsir-tafsir Pantun Sunda. Bandung: Kelir

[12] Rosidi, Ajip. (2000) Ensiklopedi Sunda: Alam, Manusia dan Budaya (Termasuk Budaya Cirebon dan Betawi).Pustaka Jaya 